M. A. Ozturk ${ }^{1}$, A. Tufan ${ }^{1}$, H. Türktaş ${ }^{1}{ }^{1}$ Gazi Univercity Faculty of Medicine Hospital, Ankara, Turkey; ${ }^{2}$ Gülhane Research and Training Hospital, Ankara, Turkey

Background: Cyclophosphamide (CYC) had a good response rates when used as an induction regimen for the treatment of connective tissue related interstitial lung disease (CTD-ILD). But the safety profile of CYC necessitates the usage of a second line treatment for maintenance

Objectives: To compare the effect of mycophonetil (MMF) and azatiyopurin (AZA) for maintanance therapy following cyclophsphomide treatment in CTD-ILD Methods: Between 2009 and 2019 all interstitial lung disease patients admitting rheumatology or pulmonology department were retrospectively evaluated and patients treated with cyclophospamide as an induction regimen and having not progression were selected. Among those, as a second line regimen treated with MMF or AZA were included. Primary end point was treatment responses at 6 th months

Results: 68 patients treated with CYC for the first line treatment. 46 patients treated with either MMF (n:22) or AZA (n:24) for the maintenance. Scleroderma patients were the largest group and consituted $63 \%$ of the population. MMF group had worse FVC values and more involvement in lung paranchyme at the begining of the treatment. In univariate analysis FVC (It) values and lung involvement (\%) on HRCT at the start of the treatment, and disease subtype were associated significantly with treatment responses.After adjusted with these factors, in multivariate analysis, AZA treatment was associated with the increased risk of progression (odds ratio $5,8,95 \% \mathrm{Cl} 1,061-31,09$ ) as compared with MMF treatment Conclusion: MMF had better results compared to AZA in the treatment of CTD-ILD, after the usage of CYC treatment.

References:

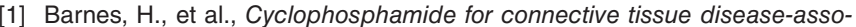
ciated interstitial lung disease. Cochrane Database Syst Rev, 2018. 1(1): p. Cd010908.

Table 1. Patient and disease characteristics at the start of the treatment and treatment responses at the 6th months of the treatment: FVC forced vital capacity

\begin{tabular}{lccr}
\hline & MMF (22) & AZA (24) & p \\
\hline Lung involvement (\%) & $36 \%$ & $23,3 \%$ & $\mathbf{0 , 0 2 2}$ \\
FVC (It) & 1,96 & 2,55 & $\mathbf{0 , 0 2 1}$ \\
FVC (\%) & $71 \%$ & $81 \%$ & $<\mathbf{0 , 0 0 1}$ \\
FVC change at 6th month (It) &,- 02 & $-0,19$ & $\mathbf{0 , 0 5 1}$ \\
FVC change at 6th month (\%) & $-0,42$ & $-5,81$ & 0,068 \\
Progression & $23,8 \%$ & $50 \%$ & $\mathbf{0 , 1 1 8}$ \\
\hline
\end{tabular}

Disclosure of Interests: None declared

DOI: 10.1136/annrheumdis-2020-eular.3879

\section{SAT0510 LONG-TERM EFFECTIVENESS OF CANAKINUMAB IN AID - INTERIM ANALYSIS OF THE CAPS SUBGROUP FROM THE RELIANCE REGISTRY}

N. Blank ${ }^{1}$, M. Borte ${ }^{2}$, I. Foeldvari ${ }^{3}$, G. Horneff ${ }^{4}$, T. Kallinich $^{5}$, B. Kortus-Goetze ${ }^{6}$, P. Oommen ${ }^{7}$, C. Schuetz ${ }^{8}$, F. Weller-Heinemann ${ }^{9}$, J. Weber-Arden ${ }^{10}$, J.

B. Kuemmerle-Deschner ${ }^{11}$. ${ }^{1}$ University Hospital, Heidelberg, Germany; ${ }^{2}$ Hospital St. Georg, Leipzig, Germany; ${ }^{3}$ Pediatric and Adolescence Rheumatology, Hamburg, Germany; ${ }^{4}$ Asklepios Clinic, Sankt Augustin, Germany; ${ }^{5}$ Charité University Medicine, Berlin, Germany; ${ }^{6}$ University Hospital, Marburg, Germany; ${ }^{7}$ Heinrich-Heine-University, Duesseldorf, Germany; ${ }^{8}$ University Hospital, UIm, Germany; ${ }^{9}$ Prof. Hess Kinderklinik, Bremen, Germany; ${ }^{10}$ Novartis Pharma GmbH, Nürnberg, Germany; ${ }^{11}$ University Hospital, Tübingen, Germany

Background: In the treatment of monogenic autoinflammatory diseases (AID), a heterogeneous group of diseases with excessive interleukin (IL)- $1 \beta$ release and severe systemic and organ inflammation, the anti-IL-1 inhibitor canakinumab (CAN) has been associated with rapid remission of symptoms in clinical trials as well as in real-life. ${ }^{1-3}$

Objectives: The aim of the RELIANCE registry is to explore long-term effectiveness and safety of CAN under routine clinical practice conditions in pediatric and adult patients with CAPS (cryopyrin-associated periodic syndromes, including Muckle-Wells syndrome [MWS], familial cold autoinflammatory syndrome [FCAS], neonatal onset multisystem inflammatory disease [NOMID]/ chronic infantile neurological cutaneous and articular syndrome [CINCA]), FMF (familial Mediterranean fever), TRAPS (tumor necrosis factor receptor-associated periodic syndrome) and HIDS/MKD (hyperimmunoglobulinemia D syndrome/ mevalonate kinase deficiency).

Methods: This prospective, non-interventional, observational study is based in Germany with a 3 -year follow-up and enrolls pediatric $\geq 2$ years and adult patients with clinically confirmed diagnoses of CAPS, FMF, TRAPS and HIDS/
MKD routinely receiving CAN. In 6-monthly visits, clinical data and patientreported outcomes are assessed. Study endpoints are long-term effectiveness and safety of CAN. Here, the CAPS cohort was analyzed.

Results: This 18-month interim-analysis includes 78 CAPS patients $49 \%$ females) enrolled by September 2019. Mean age at baseline was 25 years and mean duration of prior CAN treatment was 5.7 years. 64 patients $(82 \%)$ had MWS, 2 FCAS, 7 NOMID/CINCA, 3 atypical CAPS and 2 lacked subtype diagnosis. Disease activity, fatigue and social impairment by patients' assessment, days absent from school/work, inflammatory markers, and remission by physician assessment were evaluated at 6-monthly intervals starting at baseline with last update at 18 months of follow-up (table 1). The results demonstrate sustained remission and disease control as evaluated parameters remained stable over time. Serious adverse events were reported for 9 patients including papillitis pyrexia, tonsillitis $(n=2)$, appendicitis, chest pain, circulatory collapse, skin disorders, and preterm delivery.

Table 1. Patient and physician assessment of clinical CAPS disease activity and laboratory markers over time

\begin{tabular}{lcccc}
\hline & Baseline & 6 months & 12 months & 18 months \\
\hline Number of patients, N & 78 & 51 & 42 & 29 \\
Mean age, years (SD) & $25(4 ; 79)$ & $22(4 ; 79)$ & $20(4 ; 58)$ & $22(4 ; 54)$ \\
$\begin{array}{l}\text { Patient's assessment of disease activity } \\
\text { 0-10, }\end{array}$ & $2.2(0 ; 7)$ & $1.8(0 ; 7)$ & $2.4(0 ; 7)$ & $2.8(0 ; 8)$ \\
$\quad$ mean (min; max) & & & & \\
$\begin{array}{l}\text { Patient's assessment of fatigue 0-10 } \\
\text { Number (\%) of patients without impairment of }\end{array}$ & $2.9(0 ; 9)$ & $2.4(0 ; 8)$ & $2.8(0 ; 8)$ & $1.7(0 ; 7)$ \\
$\quad$ social life by disease & $29(76)$ & $20(61)$ & $14(67)$ \\
$\begin{array}{l}\text { Number (\%) of patients with days absent from } \\
\text { school/work }\end{array}$ & $25(32.5)$ & $11(22)$ & $14(34)$ & $15(52)$ \\
$\begin{array}{l}\text { Inflammatory markers, CRP/SAA, mean } \\
\text { (mg/dL) }\end{array}$ & 0.4 & 0.4 & 0.3 & 0.2 \\
$\begin{array}{l}\text { Number (\%) of patients in disease remission } \\
\text { (physician assessment) }\end{array}$ & $55(72)$ & $38(76)$ & $29(71)$ & $22(76)$ \\
\hline & & & & \\
\hline
\end{tabular}

Conclusion: The 18-month interim analysis of the RELIANCE study, the longest running real-life CAN registry, demonstrates that long-term CAN treatment is safe and effective in CAPS patients.

References:

[1] Lachmann et al. N Engl J Med. 2009;360(23):2416-25

[2] Kuemmerle-Deschner et al. Rheumatology (Oxford). 2016;55(4):689-96

[3] De Benedetti et al. N Engl. J Med. 2018;378(20):1908-1919

Disclosure of Interests: Norbert Blank Grant/research support from: Novartis, Sobi, Consultant of: Novartis, Sobi, Lilly, Pfizer, Abbvie, BMS, MSD, Actelion, UCB, Boehringer-Ingelheim, Roche, Michael Borte Grant/research support from: Pfizer, Shire, Ivan Foeldvari Consultant of: Novartis, Gerd Horneff Grant/research support from: AbbVie, Chugai, Merck Sharp \& Dohme, Novartis, Pfizer, Roche, Speakers bureau: AbbVie, Bayer, Chugai, Merck Sharp \& Dohme, Novartis Pfizer, Roche, Tilmann Kallinich Grant/research support from: Novartis, Consultant of: Sobi, Roche, Novartis, Birgit Kortus-Goetze Consultant of: Novartis, Prasad Oommen Consultant of: Novartis, Catharina Schuetz: None declared, Frank Weller-Heinemann: None declared, Julia Weber-Arden Employee of: I am employed by Novartis, J. B. Kuemmerle-Deschner Grant/research support from: Novartis, AbbVie, Sobi, Consultant of: Novartis, AbbVie, Sobi DOI: 10.1136/annrheumdis-2020-eular.6131

\section{SAT0511 CYTOKINES, CHEMOKINES AND INFLAMMATORY BIOMARKERS IN NEUROSARCOIDOSIS}

K. E. Byg ${ }^{1,2}$, Z. Illes ${ }^{2,3}$, T. Sejbaek ${ }^{4,5}$, A. Kindt ${ }^{6}$, T. Ellingsen ${ }^{2,7}$, H. Nielsen ${ }^{2,3}$. ${ }^{1}$ Odense University Hospital, University of Southern Denmark, Rheumatology, Odense C, Denmark; ${ }^{2}$ University of Southern Denmark, Clinical Research, Odense C, Denmark; ${ }^{3}$ Odense University Hospital, University of Southern Denmark., Neurology, Odense C, Denmark; ${ }^{4}$ South West Jutland Hospital, South Danish University Hospital, Neurology, Esbjerg, Denmark; ${ }^{5}$ University of Southern Denmark, Denmark, Regional Health Research, Odense C, Denmark; ${ }^{6}$ Odense University Hospital, University of Southern Denmark, Ophthalmology, Odense C, Denmark; ${ }^{7}$ Odense University Hospital, University of Southern Denmark., Rheumatology, Odense C, Denmark

Background: Sarcoidosis is characterized by granulomatous inflammation, which in rare cases can affect the central nervous system, neurosarcoidosis (NS).

Objectives: The aim of this study was to estimate levels of cytokines, chemokines, and vascular biomarkers in patients with NS.

Methods: In this observational, cross-sectional study, cerebrospinal fluid (CSF) and plasma were collected from biopsy-proven sarcoidosis patients with clinical suspicion of NS. They were categorized into either a NS group $(n=14)$ or a non-NS group $(n=5)$ depending on fulfilment of NS criteria. The results were 